\title{
UN MODELO PARA ESTUDIOS DE POSGRADO
}

\section{Gloria Calvo*}

El modelo de la actual Maestría en Educación como Seminario Interdisciplinario de Formación e Investigación en Calidad de la Educación encuentra sus raíces en la forma como se concibe la Facultad de Estudios Interdisciplinarios de la Universidad Javeriana, creada en noviembre de 1973.

La decisión de crear tal facultad estuvo originada por la necesidad de responder a la carencia de formación de recurso humano a nivel de posgrado, en un momento de expansión del sistema educativo en general.

Las discusiones y diferentes énfasis que ha tenido la maestría se pueden ver en los programas que ella ha ofrecido a lo largo de su historia; primeramente, la maestría fue en investigación y tecnología educativa. Su énfasis estuvo en la enseñanza de la investigación a partir del oficio de investigar lo cual permitió combinar metodologías tradicionales de trabajos de grado, con otras novedosas originadas en los equipos multidisciplinarios de investigación.

Esta estructura se mantuvo hasta 1986, año en el cual se reestructuró tanto la FEI como la Maestría.

En la estructura actual, la facultad está organizada a nivel de unidades de desarrollo ambiental; de desarrollo humano; de desarrollo de sistemas de salud y de política.

A partir de esta reestructuración toma fuerza el modelo de seminario para los estudios de posgrado, el cual se presenta en el documento a partir de la concepción de educación para el desarrollo humano.

El modelo de seminario para estudios de posgrado hace énfasis en un enfoque interdisciplinario como una forma de contribuir al desarrollo científico de las disciplinas.

Igualmente, al hacer relevante el compromiso por la calidad de la educación, el modelo de seminario requiere de una visión integral en donde se conjugue la perspectiva de las ciencias sociales a la vez que desarrolle distintos niveles y formas de educación.

El documento está conformado por dos partes: la primera, atañe al diseño curricular del programa, enfatizado en el papel de la educación en el desarrollo humano. Seguidamente expone las características estructurales del currículo de los estudios de posgrado en cuanto a los niveles de organización del mismo, su modalidad presencial concentrada, la estructura temática y el modelo triádico estructural del mismo.

En el seminario: Método de formación e investigación (CF. RAE. . .) se expone, ampliamente, el sentido de la maestría como seminario, sus características y tipos de trabajos exigidos.

\footnotetext{
* Maestría en Educación. Un modelo de seminario para estudios de posgrado. Bogotá. Facultad de Estudios Interdisciplinarios, 1992, 216 págs.
} 
El documento, en esta primera parte, también expone los procesos de evaluación y de administración académica, además de los criterios para elaborar tesis de maestría.

En la segunda parte, se presenta una descripción detallada de la estructura curricular. Se caracteriza el método de enseñanza y para cada una de las áreas electivas de énfasis, se plantea su propósito, lineamientos académicos, estructura, temática, programa de los módulos y bibliografía.

Las áreas electivas son: diseño y evaluación curricular, educación comunitaria participativa; medios educativos escritos y medios y docencia.

El documento termina con un listado de las directivas de la maestría.

Este trabajo, al presentar un modelo de seminario para los estudios de posgrado, quiere no sólo comunicar la experiencia de la facultad de estudios interdisciplinarios sino sistematizar los diferentes desarrollos de casi veinte años de labores; el texto puede servir de guía a nuevos programas de educación superior. 